\title{
A LEI N. 13.146 E SEUS REFLEXOS NO ALISTAMENTO ELEITORAL
}

\author{
Marco Aurélio Canever ${ }^{1}$
}

\section{Introdução}

Publicada no Diário Oficial, de 7 de julho de 2015, com previsão de vigência após 180 dias, a Lei n. 13.146, de 6 de julho de 2015, institui a Lei Brasileira de Inclusão da Pessoa com Deficiência (Estatuto da Pessoa com Deficiência), destinada a assegurar e a promover, em condições de igualdade, o exercício dos direitos e das liberdades fundamentais por pessoa com deficiência, visando à sua inclusão social e cidadania.

Apesar dos vários comandos que representam notável avanço para a proteção da dignidade da pessoa com deficiência, as alterações legislativas promovidas nos artigos do Código Civil que tratam da teoria das incapacidades trazem importantes consequências no alistamento eleitoral.

\section{Direitos políticos}

Os direitos políticos ou de cidadania, elementares ao estado democrático de direito, constituem o conjunto de direitos que asseguram a participação do cidadão no governo do país, como corolários do prescrito no artigo $1^{\circ}$ da Constituição Federal: "todo poder emana do povo, que o exerce por meio de representantes eleitos ou diretamente, nos termos desta Constituição".

Segundo MENDES (p. 216), "há quem situe essa categoria de direitos fundamentais ao lado das referentes aos direitos de defesa e aos direitos a prestação. Seria constituída pelos direitos orientados a garantir a participação dos cidadãos na formação da vontade do País, correspondendo ao capítulo da Constituição Federal relativo aos direitos políticos".

O conceito é bem explanado por COSTA (p. 23):

[...] podemos compreender a cidadania como o direito público subjetivo à participação política, vale dizer, ao exercício do direito de sufrágio e da elegibilidade, tal qual previsto no art. 14, caput, da CF/88. Vista e compreendida como direito público subjetivo, a cidadania possui contornos estipulados pelo ordenamento jurídico, que deter- 
mina seu conteúdo, seus pressupostos e seus limites, naquela compreensão de que o legislador é livre para determinar os efeitos jurídicos, sem embargo dos condicionamentos políticos e axiológicos, que operam no momento nomogenético.

São eles, pois, resguardados e assegurados constitucionalmente pela previsão do sufrágio universal e pelo voto direto e secreto, expressos no artigo 14 da Constituição Federal, cuja redação estabelece que: "A soberania popular será exercida pelo sufrágio universal e pelo voto direto e secreto, com valor igual para todos, e, nos termos da lei, mediante: I plebiscito; II - referendo; III - iniciativa popular".

Esse conjunto formado pela capacidade eleitoral ativa (denominada também direito de votar ou alistabilidade) e a capacidade eleitoral passiva (identificada pelo direito de ser votado ou elegibilidade) é que representa o sufrágio, instrumento político que confere validade à investidura na função pública eletiva.

Na explicação de COSTA (p. 23-24), "em verdade, o direito se sufrágio (= direito de votar; ius singulii) e a elegibilidade (= direito de ser votado; ius honorum) são espécies do gênero soberania popular (ou cidadania), como explicita o próprio art. 14 da CF/88, ao tratar conjuntamente dos dois institutos, quando da regulação sobre o modo de exercício da soberania popular: pelo sufrágio (caput) e pela elegibilidade $\left(\S 3^{\circ}\right)$ ".

O pleno gozo desses direitos contempla o exercício amplo dessas duas capacidades, de votar e ser votado, cuja mitigação é apenas permitida em casos extraordinários constitucionalmente previstos.

De fato, poder votar e ser votado é a face mais aparente dos direitos políticos. Contudo, ZAVASCKI (p. 193) dá uma amplitude mais completa ao significado, afirmando que:

[...] estar no gozo dos direitos políticos significa, pois, estar habilitado a alistar-se eleitoralmente, habilitar-se a candidaturas para cargos eletivos ou a nomeação para certos cargos públicos não eletivos (CF, arts. 87; 89, VII; $\left.101 ; 131, \S 1^{\circ}\right)$, participar de sufrágios, votar em eleições, plebiscitos e referendos, apresentar projetos de lei pela via da iniciativa popular (CF, art. 61, § 2 , art. 29, XI), propor ação popular (CF, art. 52, inc. LXXIII). Quem não está no gozo dos direitos políticos não poderá filiar-se a partido político (Lei n. 5.682, de 21.7.1971, art. 62), e nem investir-se em qualquer cargo público, mesmo não eletivo (Lei n. 8.112, de 11.12.1990, art. 52, II). Não pode, também, ser diretor ou redator-chefe de jornal ou periódico (Lei n. 5.250, de 9.2.1967, art. $72, \S 1^{\circ}$ ) e nem exercer cargo em entidade sindical (CLT, art. 530, V). 
A capacidade eleitoral ativa, que nos interessa no presente estudo, refere-se basicamente ao reconhecimento legal da qualidade de eleitor no tocante ao exercício do sufrágio. Em verdade, confunde-se com a própria definição de eleitor, que pelo Glossário Eleitoral "é o cidadão brasileiro, devidamente alistado na forma da lei, no gozo dos seus direitos políticos e apto a exercer a soberania popular, consagrada no artigo $14 \mathrm{da}$ Constituição Federal, por meio do sufrágio universal, pelo voto direto e secreto, com valor igual para todos e mediante os instrumentos de plebiscito, referendo e iniciativa popular das leis".

Como tal, a capacidade eleitoral ativa se adquire pelo alistamento perante a Justiça Eleitoral, ramo especializado do Poder Judiciário, que é o órgão estatal responsável pela administração de todo o eleitorado e pela condução das eleições, referendos e plebiscitos.

Na lição de COSTA (p. 69), "o alistamento eleitoral é o fato jurídico do qual dimana o direito de votar (ius singulii). Quando o ordenamento jurídico utiliza o signo direitos políticos, fá-lo como sinônimo de soberania popular ou cidadania. [...] Quem perde ou tem suspenso os direitos políticos, perde ou tem suspensa a própria cidadania, o próprio status civitatis".

É mediante seu ingresso no rol de votantes que a pessoa ditada de direitos políticos passará a estar apta a participar da soberania popular, segundo a qual ele, como integrante do povo, é detentor de uma parcela de todo o poder estatal.

Por tal motivo, trata-se de ato personalíssimo e, do mesmo modo que o voto, não é facultada a sua realização por internet ou procuração. Reitera-se que só pode ser solicitado pelo próprio eleitor ao funcionário da Justiça Eleitoral, que deve certificar este fato.

RAMAYANA (p. 110) complementa que "o requerimento de alistamento eleitoral serve para a entrada de dados, qualificando e inscrevendo o eleitor numa determinada zona eleitoral. [...] O requerimento de alistamento eleitoral é preenchido apenas por servidor da Justiça Eleitoral (art. $9^{\circ}$ da Resolução n. 21.538/03), que digitará as informações pessoais do eleitor".

Por força constitucional, o alistamento eleitoral é vedado aos não nacionais e aos conscritos, obrigatório para os brasileiros com idade entre 18 e 70 anos, e facultativo para os analfabetos, para quem estiver entre 16 e 18 anos e para os maiores de 70 anos de idade.

Se a regra constitucional é a alistabilidade, as hipóteses de alistamento vedado se referem àquelas expressamente consignadas na Carta 
Maior já mencionadas. E como causas restritivas de direitos, devem ser interpretadas restritivamente, pois, como já dito, a regra é o exercício dos direitos políticos.

\section{Direitos políticos e capacidade eleitoral}

Nem todas as pessoas gozam de direitos políticos plenamente (ius singulii e ius honorum). Mas como visto, uma vez conquistados, tais direitos não são intocáveis. Há as que só estão habilitadas para uma das faculdades políticas e outras que não possuem qualquer delas.

A Constituição Federal, em seu artigo 15, veda veementemente a cassação dos direitos políticos, mas permite a suspensão ou perda nos casos taxativamente previstos em seus incisos: o cancelamento da naturalização por sentença transitada em julgado; a incapacidade civil absoluta; a condenação criminal transitada em julgado, enquanto durarem seus efeitos; a recusa de cumprir obrigação a todos imposta ou prestação alternativa, nos termos do art. $5^{\circ}$, VIII; e a improbidade administrativa, nos termos do art. $37, \S 4^{\circ}$.

GOMES (p. 9) bem explica tal fenômeno jurídico:

A seu turno, perder é deixar de ter, possuir, deter ou gozar algo; é ficar privado. Como é óbvio, só se perde o que se tem. A idéia de perda liga-se à de definitividade; a perda é sempre permanente, embora se possa recuperar o que se perdeu. Já a suspensão - na definição de Cretella Júnior (1989, v. 2, p. 1118) - "é interrupção temporária daquilo que está em curso, cessando quando terminam os efeitos de ato ou medida anterior". Trata-se, portanto, de privação temporária de direitos políticos.

Por essa razão, a plenitude dos direitos políticos apresenta íntima relação com o alistamento eleitoral, pois o pleno exercício dos direitos políticos se adquire com tal ato, e se mantém pleno enquanto os direitos políticos não forem suspensos ou perdidos. Parece-nos que um não vive nem sobrevive sem o outro.

Pelo fato de que não se pode falar em suspensão do que nunca se teve, uma outra discussão é aparentemente necessária acerca do alcance do disposto no artigo 15 da Constituição, a fim de que não compreenda apenas as hipóteses de perda ou suspensão superveniente à aquisição dos direitos políticos, mas também aquelas situações nas quais pelas mesmas hipóteses nem se chega a possuí-los. 
GOMES (p. 9-12) levantou a questão:

Só pode ser suspenso algo que já existia e estava em curso. Assim, se a pessoa ainda não detinha direitos políticos, não pode haver suspensão. A Lei Maior não fala em impedimento, embora se possa cogitar dele. Consiste o impedimento em obstáculo à aquisição dos direitos políticos, de maneira que a pessoa não chega a alcançá-los enquanto não removido o óbice. Haverá impedimento, e.g., quando o absolutamente incapaz portar anomalia congênita, permanecendo nesse estado até atingir a idade adulta. [...] Nesse caso, é impróprio falar-se de suspensão, que pressupõe o gozo anterior de direitos políticos. Tampouco se pode falar de perda, pois não se perde o que não se tem. Mais correto será pensar em impedimento, pois a incapacidade congênita é fator obstativo para a aquisição dos direitos políticos.

De fato, a norma constitucional não é expressa a ponto de impedir o alistamento eleitoral dos que tenham seus direitos políticos suspensos e, aparentemente, essa omissão do constituinte originário é inconciliável com as disposições do artigo 15.

Embora desnecessário, MENDES (p. 919) traçou a solução, ainda que para semelhante caso, ao afirmar que "cuidar-se-ia de uma 'lacuna' suscetível de ser superada com base nos próprios princípios estruturantes do sistema constitucional, suficientes a legitimar uma cláusula implícita de justificasse outras exceções ao alistamento obrigatório [...]".

Assim, além de se consubstanciarem em causas de perda e suspensão dos direitos políticos eventualmente já adquiridos, as hipóteses do artigo 15 da Constituição Federal se revelam verdadeiras hipóteses de impedimento ao alistamento eleitoral e da própria aquisição de tais direitos.

\section{Capacidade civil e capacidade eleitoral}

Ao estudo proposto interessa especialmente a suspensão do exercício dos direitos políticos decorrente da declaração da incapacidade civil absoluta, prevista no inciso II do artigo 15 da Constituição Federal.

Parafraseando o já afirmado anteriormente, além de causa de suspensão dos direitos políticos eventualmente já adquiridos, a incapacidade civil absoluta se revela verdadeiro impedimento ao alistamento eleitoral e da própria aquisição de tais direitos. 
Para compreensão do instituto da capacidade, suficientes são as lições de $\operatorname{COSTA}($ p. 71):

Todo ser humano possui personalidade desde o nascimento com vida. À personalidade corresponde a capacidade de direito, que é a faculdade de adquirir direitos e deveres na ordem jurídica. Toda pessoa tem capacidade de direito, como enuncia o art. $1^{\circ}$ do Código Civil Brasileiro de 2002. Nada obstante, o ser sujeito de direito subjetivo pode vir apoucado da capacidade de dele gozar e flui, com limitações ao exercício. [...] No direito brasileiro, todos nascem com capacidade de direito. Todavia, a capacidade de agir não é obtida quando do nascimento com vida. [...] A incapacidade absoluta é ausência ou perda da capacidade de agir.

Já GOMES (p. 11) complementa acerca do inciso II do artigo 15 da Constituição Federal, que "a hipótese em apreço remete ao artigo $3^{\circ}$, II, do vigente Código Civil. A incapacidade absoluta implica a completa vedação do indivíduo para o exercício de atos da vida civil, já que ele se torna inapto para conduzir-se com independência, autonomia e eficiência na vida, de maneira a reger sua pessoa e seus bens. O incapaz atua por meio de seus representantes legais, que realizam os atos por ele".

O vínculo entre capacidade civil e capacidade política é bem explanada por MENDES (p. 919):

De qualquer sorte, capacidade civil e capacidade política estão estritamente relacionadas. [...] A capacidade para votar e ser votado atinge os cidadãos que ainda não alcançaram a maturidade - que são os menores de 16 anos, coincidente com a menoridade civil (incapacidade absoluta) - assim como os que padecem de alguma doença mental e, portanto, não possuem o discernimento necessário para a prática dos atos da vida política.

Em voto vista proferido no PA n. 19.297, o eminente doutrinador e Ministro Gilmar Mendes bem expôs o alcance na norma:

O inciso II prevê a hipótese de suspensão dos direitos políticos em virtude de incapacidade civil absoluta. Não trata o texto constitucional das hipóteses de incapacidade civil absoluta em decorrência da idade, no caso dos menores de 16 anos (inciso I do art. $3^{\circ}$ do Código Civil), que não são cidadãos politicamente ativos. A suspensão apenas se aplica, logicamente, aos que já gozam de direitos políticos. Portanto, o inciso II abarca os cidadãos que, segundo o art. $3^{\circ}$ do Código Civil, por enfermidade ou deficiência mental, não tenham o necessário discernimento para a prática dos atos da vida civil e os que, mesmo por causa transitória, não puderem exprimir sua vontade. 
Adequadas são as conclusões de COSTA (p. 73) de que "qualquer das hipóteses previstas na legislação civil que se subsumam à alencada no art. 15, inciso II, da CF/88, importam a suspensão dos direitos políticos do nacional, dando ensejo a exclusão do eleitor do corpo de eleitores, com o cancelamento de sua inscrição eleitoral (art. 71, inc. II, do Código Eleitoral)".

Em verdade, o que ocorre, na prática, nesses casos, é a suspensão da inscrição (se existente) ou o indeferimento da inscrição (caso inexistente e uma vez requerida).

Discorrendo sobre a suspensão de direitos políticos em virtude da aplicação de medida de segurança, com propriedade, MENDES (p. 920) já alertou sobre a razão de ser do impedimento:

A Constituição, ao tratar desses casos de incapacidade, apenas se ateve ao âmbito civil, estabelecendo de forma expressa, precisamente no art. 15, II, a possibilidade de suspensão dos direitos políticos dos cidadãos que padecem de incapacidade civil absoluta. [...] Se, todavia, a teleologia constitucional procura excluir do processo político-eleitoral todos aqueles que ainda não possuem a devida capacidade para a prática dos atos da vida política, seria um total contrassenso a interpretação desses dispositivos constitucionais que levasse ao entendimento de que os indivíduos submetidos a medidas de segurança, por debilidade mental, pudessem gozar plenamente de seus direitos políticos, podendo votar e, ao que causa perplexidade, ser votados.

Com efeito, toda a suspensão dos direitos políticos em virtude da incapacidade civil absoluta está assentada no disposto na legislação ordinária, qual seja, o Código Civil Brasileiro ( Lei n. 10.406, de 10 de janeiro de 2002).

Dispõe o Código Civil, em sua redação ainda em vigor, que:

Art. $3^{\circ}$ São absolutamente incapazes de exercer pessoalmente os atos da vida civil:

I - os menores de dezesseis anos;

II - os que, por enfermidade ou deficiência mental, não tiverem o necessário discernimento para a prática desses atos;

III - os que, mesmo por causa transitória, não puderem exprimir sua vontade.

Art. $4^{\circ}$ São incapazes, relativamente a certos atos, ou à maneira de os exercer: 
I - os maiores de dezesseis e menores de dezoito anos;

II - os ébrios habituais, os viciados em tóxicos, e os que, por deficiência mental, tenham o discernimento reduzido;

III - os excepcionais, sem desenvolvimento mental completo;

IV - os pródigos.

Parágrafo único. A capacidade dos índios será regulada por legislação especial.

Percebe-se que a enumeração dos casos de incapacidade (relativa e absoluta) na lei está intimamente ligada a condições que comprometem na formação ou na manifestação de vontade.

PEREIRA (p. 171) bem pondera sobre os motivos que fundamentam a incapacidade civil no Direito Brasileiro:

O instituto das incapacidades foi imaginado e construído sobre uma razão moralmente elevada, que é a proteção dos que são portadores de uma deficiência juridicamente apreciável. Esta é a idéia fundamental que o inspira, e acentuá-lo é de suma importância para a sua projeção na vida civil, seja no tocante à aplicação dos princípios legais definidores, seja na apreciação dos efeitos respectivos ou no aproveitamento e na ineficácia dos atos jurídicos praticados pelos incapazes. A lei não institui o regime das incapacidades com o propósito de prejudicar aquelas pessoas que delas padecem, mas, ao revés, com o intuito de lhes oferecer proteção, atendendo a que uma falta de discernimento, de que sejam pacientes, aconselha tratamento especial, por cujo intermédio o ordenamento jurídico procura restabelecer um equilíbrio psíquico, rompido em conseqüência das condições peculiares dos mentalmente deficitários.

Tratam tais dispositivos da incapacidade civil e as disposições do artigo $3^{\circ}$, como já dito, abarcam as situações de impedimento da aquisição e exercício dos direitos políticos, tendo especial consequência jurídica no âmbito do Direito Eleitoral.

Nas lições de CERQUEIRA (p. 122):

[...] segundo o art. $3^{\circ}$ do novo Código Civil, a incapacidade absoluta é atribuída aos que, por enfermidade ou deficiência mental, não tiverem o necessário discernimento para a prática desses atos e aos que, mesmo por causa transitória, não puderem exprimir sua vontade, além dos menores de 16 anos de idade) — todas as causas devem ser reconhecidas em sentença transitada em julgado do juízo cível, ou seja, o registro da informação da suspensão no cadastro só se dará mediante comunicação da autoridade judiciária que deter- 
minar a restrição, exceto para os menores de 16 anos, cuja incapacidade absoluta é presumida por lei [...].

Basicamente, a incapacidade absoluta decorre de duas causas basilares: idade e enfermidade.

A discussão acerca da razão de ser da idade de cessação da incapacidade civil absoluta aos 16 anos é dispensável para fins eleitorais, já que tal idade é, coincidentemente, a mínima exigida para a aquisição dos direitos políticos.

Assim, para nosso estudo, apenas as causas que atingem o intelecto humano nos interessam, pois elas atingem a capacidade eleitoral ativa mesmo após o implemento da idade de sua aquisição.

Esclarecedoras são as palavras de PEREIRA (p. 175), ainda que em estudo as disposições do Código Civil, de 1916:

[...] Sem escravização à expressão vocabular do texto, hoje é pacífica e tranqüila a hermenêutica no sentido de que a incapacidade por loucura resulta de todo mau funcionamento dos centros cerebrais, em razão de enfermidade ou de acidente, que implique supressão de entendimento ou da vontade, ou redução do discernimento a ponto de comprometer a conduta, ou torne o paciente inapto a reger sua pessoa e administrar os seus bens, não dissentindo o direito brasileiro da doutrina dominante entre os melhores autores.

Mais atuais são as lições de GONÇALVES (p. 72):

O novo diploma usa expressão genérica ao referir-se à falta do necessário discernimento para os atos da vida civil, compreensiva de todos os casos de insanidade mental, permanente e duradoura, caracterizada por graves alterações das faculdades psíquicas. Incluiu a expressão "ou deficiência mental" porque na enfermidade propriamente dita não se contém a deficiência mental. Mas não deixa de estabelecer uma gradação necessária para a debilidade mental, ao considerar relativamente incapazes os que, "por deficiência mental, tenham o discernimento reduzido" (art. $4^{\circ}$ ), referindo-se aos fracos da mente.

A fórmula genérica empregada pelo legislador abrange todos os casos de insanidade mental, provocada por doença ou enfermidade mental congênita ou adquirida, como a oligofrenia e a esquizofrenia, por exemplo, bem como por deficiência mental decorrente de distúrbios psíquicos, desde que em grau suficiente para acarretar a privação do necessário discernimento para a prática dos atos da vida civil. 
Vale observar que a incapacidade civil relativa não exclui o exercício dos direitos políticos, posto que não há qualquer fator impeditivo ao alistamento eleitoral e ao voto que - caso não se trate de pessoa analfabeta - será obrigatório entre os 18 e os 70 anos de idade.

MENDES (p. 919) relembrou que "controvérsia interessante colocouse perante a Justiça Eleitoral a propósito da obrigatoriedade do voto dos portadores de deficiência grave, cuja natureza e situação impossibilite ou torne extremamente oneroso o exercício de suas obrigações eleitorais. [...] Argumentou-se que algumas pessoas apresentam deficiências que praticamente tornam impossível o exercício de suas obrigações eleitorais $[\ldots] "$.

Assim, se o exercício das obrigações eleitorais vier a se tornar impossível ou excessivamente oneroso, a pessoa relativamente incapaz em virtude de alguma deficiência poderá requerer certidão de quitação com a Justiça Eleitoral, com prazo de validade indeterminado, que - apesar de não impedir o alistamento nem o exercício do voto (que permanecem obrigatórios) - afasta a aplicação de multa pelo não alistamento ou pela ausência à votação (arts. $2^{\circ}$ e $3^{\circ}$ da Res. n. 21.920/2004).

Por outro lado, a Justiça Eleitoral também garantiu à pessoa com deficiência a possibilidade de receber ajuda para votar, concluindo que, entre o direito ao voto e o sigilo do voto, deve prevalecer o primeiro, podendo, inclusive, uma pessoa de confiança entrar junto, na cabine de votação, e executar fisicamente a escolha feita pelo eleitor.

\section{Capacidade eleitoral e a Lei n. 13.146/2015}

Finalmente, a Lei n. 13.146/2015, batizada de Lei Brasileira de Inclusão da Pessoa com Deficiência, conceitua a pessoa com deficiência em seu artigo $2^{\circ}$ como "aquela que tem impedimento de longo prazo de natureza física, mental, intelectual ou sensorial, o qual, em interação com uma ou mais barreiras, pode obstruir sua participação plena e efetiva na sociedade em igualdade de condições com as demais pessoas".

Dentre outras disposições, referida norma tratou de alterações no Código Civil, no Código Eleitoral e em outros diplomas legislativos vigentes.

A mais impactante disposição da novel legislação civil no âmbito eleitoral ocorreu justamente na teoria da capacidade do Direito Brasileiro e, por via de consequência, da capacidade eleitoral. 
Eis o teor da inovação legislativa:

Art. 114. A Lei n. 10.406, de 10 de janeiro de 2002 (Código Civil), passa a vigorar com as seguintes alterações:

Art. $3^{\circ}$ São absolutamente incapazes de exercer pessoalmente os atos da vida civil os menores de 16 (dezesseis) anos.

I - (Revogado);

II - (Revogado);

III - (Revogado)." (NR)

"Art. $4^{\circ}$ São incapazes, relativamente a certos atos ou à maneira de os exercer:

$[\ldots]$

II - os ébrios habituais e os viciados em tóxico;

III - aqueles que, por causa transitória ou permanente, não puderem exprimir sua vontade;

$[\ldots]$

Parágrafo único. A capacidade dos indígenas será regulada por legislação especial. (NR)

Como se vê, a incapacidade absoluta foi reduzida apenas para aquela causa baseada na idade do indivíduo, em razão da sua presumida inexperiência para a prática dos atos da vida civil.

Todas as demais hipóteses de incapacidade civil absoluta decorrente da falta de discernimento necessário para a prática de atos e de impossibilidade de expressão da vontade foram abolidas, e não mais representam óbices para a prática de atos da vida civil por quem lhes apresenta.

Ao que parece, o objetivo da lei, no ponto da alteração sobre incapacidade, foi ampliar ao máximo a capacidade da pessoa com alguma "deficiência", como medida de inclusão e reconhecimento de sua condição social.

Mas, do exposto até agora, a alteração legislativa promovida pela Lei n. 13.146/2015 esvaziou o conteúdo do inciso II do artigo 15 da Constituição Federal, já que o único critério mantido de incapacidade civil absoluta não tem aplicabilidade prática no âmbito eleitoral.

Assim agindo, o legislador pátrio retirou do ordenamento jurídico as hipóteses impedientes de realização do alistamento eleitoral, já que além de causa de suspensão dos direitos políticos já adquiridos, a incapacida- 
de civil absoluta também era verdadeiro impedimento à própria aquisição de tais direitos.

Assim, todas aquelas hipóteses de impedimento para aquisição dos direitos políticos, vale dizer, impedimentos para aquisição da capacidade eleitoral ativa em virtude da inexistência ou impossibilidade na manifestação da vontade, foram eliminadas como consequência das alterações promovidas no instituto da incapacidade civil absoluta, ainda que a legislação tenha preservado a incapacidade civil relativa daqueles que não puderem exprimir sua vontade.

Mais que isso, a consequência é a de que, com a exclusão da possibilidade de interpretação da incapacidade civil absoluta como impedimento à própria aquisição de tais direitos, a rigor, o alistamento e o voto tornaram-se obrigatórios para aqueles que antes se situavam na condição de impedidos de obtê-lo.

Nota-se, ainda, que essas consequências, no plano jurídico-eleitoral, foram previstas e reforçadas pelo legislador na Lei n. 13.146/2015, que, no seu teor, trouxe outras disposições específicas que levam ao entendimento de que o objetivo é realmente assegurar a capacidade eleitoral àquelas pessoas que se enquadram no novo conceito de pessoa com deficiência, e não mais de pessoa absolutamente incapaz.

Eis o teor:

Art. 76. [...]

$\S 1^{\circ}$ À pessoa com deficiência será assegurado o direito de votar e de ser votada, inclusive por meio das seguintes ações:

$[\ldots]$

\section{Art. 85. [...]}

$\S 1^{\circ} \mathrm{A}$ definição da curatela não alcança o direito ao próprio corpo, à sexualidade, ao matrimônio, à privacidade, à educação, à saúde, ao trabalho e ao voto.

À primeira vista, parece o caso de uma norma teratológica, cuja aplicabilidade será difícil no âmbito eleitoral. Imagine-se um esquizofrênico, em pleno surto, comparecendo a um cartório com manifesto intuito de obter sua inscrição eleitoral. A rigor, não há qualquer fator impeditivo para o alistamento eleitoral e o voto que, caso não seja pessoa analfabeta, será inclusive obrigatório se o requerente tiver entre 18 e 70 anos de idade. 
Salvo se ostentar a condição de analfabeto - aqui é importante alertar que tal conceito é divergente no âmbito eleitoral -, não haverá qualquer motivo impediente a que, uma vez que conquiste a capacidade eleitoral ativa, um eleitor com graves alterações das faculdades psíquicas conquiste a condição de candidato.

Em relação à obrigatoriedade do alistamento e do voto que exsurge da nova redação, o que resta é a possibilidade de reconhecer a facultatividade do alistamento eleitoral daqueles que não tem consciência do seu significado invocando sua condição de analfabeto, caso a ostentarem, ou se o exercício das obrigações eleitorais vier a se tornar impossível ou excessivamente oneroso, o fornecimento de certidão de quitação com a Justiça Eleitoral com prazo de validade indeterminado.

\section{Conclusão}

As capacidades de votar e ser votado integram o conteúdo dos direitos políticos. O pleno exercício de tais direitos somente pode ser constitucionalmente restringido, nas hipóteses em que tanto o direito de votar quanto o de ser votado não são reconhecidos, ou apenas é deferido o direito de votar.

Além de ser causa de suspensão dos direitos políticos eventualmente já adquiridos, a incapacidade civil absoluta se revela verdadeiro impedimento ao alistamento eleitoral e da própria aquisição de tais direitos, por força do disposto no artigo 15 do inciso II da Constituição Federal.

A suspensão dos direitos políticos em virtude da incapacidade civil absoluta está alicerçada no Código Civil Brasileiro, que a atribui aos que, por enfermidade ou deficiência mental, não tiverem o necessário discernimento para a prática desses atos e aos que, mesmo por causa transitória, não puderem exprimir sua vontade, além dos menores de 16 anos de idade.

As alterações promovidas pela Lei n. 13.146/2015 esvaziaram o conteúdo do inciso II do artigo 15 da Constituição Federal, já que o único critério mantido de incapacidade civil absoluta não tem aplicabilidade prática no âmbito eleitoral.

Com certeza, por melhores que sejam as intenções, as alterações são mais uma pérola que nos foi dada pelos legisladores brasileiros. 


\section{Referências}

BRASIL, Tribunal Superior Eleitoral. Processo Administrativo n. 19.297. Relator: Min. Francisco Peçanha Martins. 2006.

CERQUEIRA, Thales Tácito; CERQUEIRA, Camila Albuquerque. Direito Eleitoral esquematizado. 2. ed. rev. e atual. São Paulo: Saraiva, 2012.

COSTA, Adriano Soares da. Instituições de Direito Eleitoral. 7. ed. rev. ampl. e atual. Rio de Janeiro: Lumen Juris, 2008.

GOMES, José Jairo. Direito Eleitoral. 8. ed. rev. ampl. e atual. São Paulo: Atlas, 2012.

GONÇALVES, Carlos Roberto. Direito Civil Brasileiro. v. 1. Parte Geral. 10. ed. São Paulo: Saraiva, 2012.

MENDES, Gilmar Ferreira. BRANCO, Paulo Gustavo Gonet. Curso de Direito Constitucional. 7. ed. rev. e atual. São Paulo: Saraiva, 2012.

PEREIRA, Caio Mário da Silva. Instituições de Direito Civil. v. 1. 19. ed. Rio de Janeiro: Forense, 2001.

RAMAYANA, Marcos. Direito Eleitoral. 8. ed. Rio de Janeiro: Impetus, 2008.

ZAVASCKI, Teori Albino. Direitos políticos: perda, suspensão e controle jurisdicional. Revista da Associação dos Juízes do Rio Grande do Sul, Porto Alegre, n. 61, p. 193, jul./1994.

\section{Notas}

${ }^{1}$ Bacharel em Direito. Especialista em Direito Administrativo e Gestão Pública. Analista Judiciário do Tribunal Regional Eleitoral do Paraná. 